\title{
Contraste na Infraestrutura Urbanística de Teresina - PI: O Caso do Morro da Garrincha e Miranda Dantas.
}

Contrast in the Urbanistic Infrastructure of Teresina - PI: "Morro da Garrincha and Miranda Dantas" Case of Study.

Contraste en la Infraestructura Urbanística de Teresina - PI: El Caso Morro da Garrincha y Miranda Dantas.

Cinthia Bessa Graduando (a) em Arquitetura e Urbanismo, UNINOVAFAPI, Brasil cinthia-bessa@hotmail.com

Kelly Negreiros Graduando (a) em Arquitetura e Urbanismo, UNINOVAFAPI, Brasil beanegreiross@gmail.com

Rômullo Mota Graduando (a) em Arquitetura e Urbanismo, UNINOVAFAPI, Brasil romullo.mota@live.com 
RESUMO

A instabilidade urbana e habitacional é alarmante na capital do Piauí, Teresina, - fator que desencadeia o surgimento de aglomerados subnormais. O presente artigo tem como principal objetivo analisar a atuação do Estado na garantia dos direitos sociais dos habitantes dos aglomerados: Morro da Garrincha e Miranda Dantas, à luz do artigo $6^{\circ}$ da Constituição, que prevê a garantia de direitos sociais a educação, a saúde, o trabalho, a moradia, o lazer, a segurança, a previdência social, a proteção à maternidade e à infância, a assistência aos desamparados. Nesse sentido, foram realizadas visitas in loco e revisões da literatura acerca do urbanismo e dos aglomerados subnormais. Após a coleta de dados, esses foram analisados com vista aos principais aspectos identificados: infraestrutura das habitações, vias de circulação, serviços públicos oferecidos na região.

PALAVRAS-CHAVE: Urbanismo. Aglomerados. Infraestrutura.

\section{ABSTRACT:}

Urban and housing instability is alarming in the capital of Piaui - Teresina - a factor that triggers the emergence of subnormal clusters. The main objective of this article is to analyze the role of the State in guaranteeing the social rights of the inhabitants of the agglomerates: Morro da Garrincha and Miranda Dantas, in the light of Article 6 of the Constitution, which provides for the guarantee of social rights for education, health, work, housing, leisure, security, social security, maternity and child protection, assistance to the homeless. In this sense, there were technical visits in loco and literature reviews on urbanism and subnormal clusters. After data collecting, these were analyzed in view of the main unfavorable aspects identified: housing infrastructure; roads; public services offered in the region.

KEYWORDS: urbanismo; clusters; infrastructure.

\section{RESUMEN:}

La inestabilidad urbana y habitacional es alarmante en la capital de Piaui - Teresina - factor que desencadena el surgimiento de aglomerados subnormales. El presente artículo tiene como principal objetivo analizar la actuación de los Estados en la garantía de los derechos sociales de los habitantes de los aglomerados: Morro da Garrincha y Miranda Dantas, a la luz del artículo 6 de la Constitución, que prevé la garantía de derechos sociales a la educación, el trabajo, la vivienda, el ocio, la seguridad, la seguridad social, la protección a la maternidad y la infancia, la asistencia a los desamparados. En ese sentido, se realizaron visitas in situ y revisiones de la literatura acerca del urbanismo y de los aglomerados subnormales. Después de la recolección de datos, estos fueron analizados con vistas a los principales aspectos desfavorables identificados: infraestructura de las viviendas, vías de circulación, servicios públicos ofrecidos en la región.

PALABRAS-CLAVE: urbanismo; racimos; infraestructura. 


\section{INTRODUÇÃO}

As cidades enfrentam diversos entraves na busca pela eficiência do sistema urbano e garantia da qualidade de vida da população. Existem vários conceitos e instrumentos que são aplicados dentro da concepção e transformação da infraestrutura urbana, dentre eles, o urbanismo. Palavra que compõe um dos vocábulos de grande importância dentro do dialeto arquitetônico, o urbanismo é definido como "a remodelação, extensão e embelezamento de uma cidade, levados a efeito, mediante um estudo metódico da geografia humana e da topografia urbana sem descurar as soluções financeiras." (AGACHE, 1931, p. 118).

A Carta de Atenas de 1933 sintetiza a concepção do "Urbanismo Racionalista", utilizando como aspectos primordiais em seu debate: a importância do planejamento regional e infraestrutural urbano; a implementação do zoneamento através da segregação de finalidades em zonas distintas, com o objetivo de evitar conflito de finalidades incompatíveis; a subordinação da propriedade particular do solo urbano ao interesse público; a verticalização dos prédios localizados em áreas de vegetação; a industrialização dos componentes e a padronização das construções e de seus processos construtivos (LE CORBUSIER, 2004).

Apesar de algumas experiências que obtiveram sucesso em sua aplicação, o conceito da Carta de 1933 não atende mais aos preceitos estabelecidos atualmente de urbanismo sustentável. À medida que o crescimento populacional alcançou seu ápice, as áreas verdes foram se extinguindo devido à demanda habitacional. Tal fato gerou a necessidade de se planejar o urbanismo das cidades, levando em consideração o espaço mínimo definido pela legislação de cada prefeitura, destinado para áreas de vegetação nativa e/ou implantadas para melhoramento do microclima de cada região (ASCHER, 2010).

O Brasil, em sua naturalidade, após a segunda metade do século XX passou por um acentuado crescimento da urbanização, de um modo acelerado e irregular sem planejamento urbano. Gerando assim, uma mescla de situações no contexto urbano, em sua maior parte negativas, dentre elas é possível enumerar: a favelização, violência urbana, poluição, enchentes (COSTA et al, 2016, p. 5).

Dentro dessa gama de situações geradas, a favelização se tornou uma problemática considerável. A análise desse processo foi sistematizada através do conceito de aglomerado subnormal que, de acordo com o Instituto Brasileiro de Geografia e Estatística - IBGE é definido como:

\footnotetext{
Conjunto constituído por 51 ou mais unidades habitacionais caracterizadas por ausência de título de propriedade e pelo menos uma das características abaixo: irregularidade das vias de circulação e do tamanho e forma dos lotes e/ou carência de serviços públicos essenciais (como coleta de lixo, rede de esgoto, rede de água, energia elétrica e iluminação pública). (IBGE, 2010).
}

Segundo Ermínia Maricato (2000), é alarmante o fato do crescimento das periferias das metrópoles ultrapassarem o crescimento dos núcleos centrais, pois denota assim o número de regiões em precariedade. Afirma ainda, que o Brasil sofreu um crescimento econômico 
acelerado e desordenado entre as décadas de 1940 a 1980 sem modificar a desigualdade social, onde o declínio econômico nos anos de 80 a 90 aprofundou a exclusão social.

De acordo com os dados de pesquisa de Lima Neto, Krause e Nadalin (2014), nas capitais, assenta-se uma contradição em relação às metrópoles: a presença de aglomerados é maior em municípios de área de abrangência, 11,22\% contra 8,49\% nos núcleos. Em 2000, essa correlação era maior na área de abrangência $(3,45 \%)$ que nos núcleos $(3,23 \%)$, apesar de serem números muito mais próximos.

Esse cenário é explicado pelo aumento da mancha urbana metropolitana, evidenciado principalmente nas margens do município-núcleo. Isso denota que a marginalização da população em geral é acompanhada pela periferização da faixa social de menor renda que estabelece moradia em assentamentos subnormais (NETO, KRAUSE e NADALIN, 2014).

Neto, Krause e Nadalin (2014) destacam que uma tendência existente é o estabelecimento de assentamentos informais em vários estratos de uma mesma rede de abrangência de uma região metropolitana. Dessa maneira, é possível perceber que as interações existentes entre os centros urbanos também geram efeitos no processo de "subnormalização" do território. Tal fato é mais explícito em regiões do território brasileiro nas quais a malha urbana é mais estruturada, ou seja, "com a presença de níveis encaixados e situados a intervalos regulares" (IBGE, 2008), o que ocorre em estados da região do centro-sul brasileiro.

No contexto urbanístico brasileiro, Teresina destaca-se por ter sido a primeira capital planejada e construída durante o regime monárquico. A história de sua criação e os preceitos de seu planejamento possuem elementos próprios do planejamento urbanístico do Brasil Colonial. Sua concepção e representação gráfica do plano inicial apontam que o desenho urbano de Teresina, capital do Piauí, é resultado de influências da rígida legislação de Portugal para formação de vilas e cidades coloniais no Brasil (BRAZ E SILVA, 2018).

Em sua concepção, Teresina teve seu traçado de cidade minunciosamente projetado, pelo fato de ter sido planejada para ser a nova capital do Piauí, a partir de 1852. Seu fundador, o Conselheiro Saraiva, Presidente da Província do Piauí, elegeu a localidade de implantação levando em conta fatores comerciais. Dessa maneira, escolheu um lugar "alto e aprazível" à margem direita do rio Parnaíba, no topo do planalto que se forma entre os rios Parnaíba e Poti (D'ALENCASTRE, 1857, p.116,).

Na Era Vargas, alguns investimentos na infraestrutura urbana de Teresina foram feitos, tais como: o edifício do Liceu Piauiense (1936), hoje Colégio Estadual Zacarias de Góis e a construção do Hospital Getúlio Vargas (1941), que foi considerado, na época, a maior unidade médico-hospitalar do Nordeste. Essas obras deram à capital um status de polo referencial na área da saúde e educação básica, gerando grande fluxo de pessoas e renda para o local (COSTA et al, 2016, p. 5).

Apesar de representarem um avanço quanto aos investimentos às medidas desenvolvidas, durante o período de 1930, esses e outros investimentos ainda não representavam ações de planejamento público eficaz a grandes problemas. Não apresentando solução para a questão habitacional decorrente do crescimento da cidade no contexto teresinense, portanto, essas 
melhorias foram consideradas muito mais medidas de embelezamento e saneamento (COSTA et al, 2016).

As mudanças implementadas, em sua maioria, foram consequência do modernismo incorporado à cidade. Este se manifestou inicialmente na arquitetura oriundo dos novos pioneiros no comércio de Teresina. Nessa época, a parcela da sociedade de maior poder aquisitivo, ao passar por capitais como Belo Horizonte, Rio de Janeiro, Recife, nas quais o modernismo já havia se estabelecido, passaram a implementá-lo na concepção de suas casas (COSTA et al, 2016).

Somado a esses fatores, a partir da década de 1950, a medida que o Brasil sofria um processo acelerado de urbanização, Teresina passou a apresentar um aumento demográfico, agravando o problema habitacional. Foi a partir desse momento que ações do Poder Público direcionado ao desenvolvimento e planejamento urbano patrocinaram obras de infraestrutura básica. Assim, na década de 1960, com a elaboração do Primeiro Plano de Desenvolvimento Local Integrado (PDLI), foi introduzido um diagnóstico da cidade e representou uma mudança na forma de organização do urbanismo da cidade, sendo criada a primeira lei de zoneamento da capital (COSTA et al, p. 5, 2016).

$\mathrm{Na}$ busca de um novo panorama para Teresina, questões como a política habitacional passaram a ser tratadas com maior relevância. Sendo assim, muitos foram os investimentos neste setor que carecia de planejamento e organização decorrente do crescimento da população teresinense acima da média nacional que era ocasionado pelo fluxo de pessoas do interior que buscavam melhorias na qualidade de vida (COSTA et al, p. 5, 2016).

$\mathrm{Na}$ tentativa de atender a demanda habitacional foi inaugurada a Companhia de Habitação COHAB-PI em 1965, através da qual, muitos conjuntos habitacionais foram criados. Além disso, com o período do "milagre econômico" o seguimento da construção civil habitacional teve ainda mais recursos. Assim foram construídas em Teresina mais de 38.000 unidades habitacionais, abrigando mais de 150.000 pessoas até a extinção do Banco Nacional de Habitação (TERESINA, 2015).

Nesse contexto, à medida que a cidade de Teresina crescia rumo à periferia por meio da construção de conjuntos habitacionais que, de acordo com Lima (2007) geralmente localizamse em regiões distantes do centro ou mesmo fora do perímetro urbano, grandes vazios urbanos eram formados, incitando o surgimento de aglomerados subnormais. O processo de favelização do espaço urbano teresinense foi influenciado pela extinção do BNH, em 1986, e consequente diminuição dos investimentos do Estado na construção de habitações de interesse social.

Porém, foi em meados de 1980 e 1990 que as favelas se tornaram mais frequentes no perímetro urbano de Teresina. De acordo com Lima (2003), a implantação de aglomerados subnormais é balizada pela necessidade da população que obedece a uma tendência de localizar-se próximo a conjuntos habitacionais.

Isso se deve ao fato de que as áreas de conjuntos, teoricamente, possuem maior acesso aos serviços urbanos, mesmo que esses polos se localizem nas margens da cidade, ou seja, na nova região periférica. Essa região se redesenha, também pela apropriação de vácuos urbanos e 
pelo adensamento de áreas habitadas, em virtude da construção de novos conjuntos habitacionais (LIMA, 2003, p.50).

O processo de formação dos aglomerados urbanos apresenta variações de acordo com a região administrativa na qual se localiza. Esse fato se deve ao quadro espacial de Teresina que apresenta diferenças regionais em sua organização. Como exemplo disso, é possível destacar a região norte que, de acordo com Lima (2010), é considerada a região mais pobre da cidade, em vista as recorrentes enchentes, o processo de construção dos aglomerados deu-se em seus espaços vazios, em especial a partir da década de 1970. Já na região Sul, o processo de favelização se deu em virtude do processo de urbanização. Na região Leste, embora tradicionalmente uma zona de população de renda alta, nas últimas décadas, as áreas mais distantes do Centro estão sendo ocupadas pela a construção de inúmeros aglomerados subnormais.

De acordo com a Secretaria Municipal de Planejamento - SEMPLAN (2016), na zona urbana de Teresina, existem 111 aglomerados subnormais, distribuídos entre as quatro regiões administrativas da cidade de acordo com os dados da tabela 1. É possível observar que a maioria dos aglomerados está localizada nas regiões Sul e Leste da cidade, denotando o grau de favelização de tais zonas (SILVA, p. 103, 2017).

Tabela 1 - Quantidade de aglomerados subnormais por regiões de Teresina.

\begin{tabular}{ccc} 
Regiõs Administrativas & № de aglomerados & № de domicílios \\
\hline Centro Norte & 25 & 7756 \\
Leste & 32 & 10.906 \\
Sul & 33 & 11.635 \\
Sudeste & 21 & 4.499
\end{tabular}

Fonte: SEMPLAN (2016).

O recente levantamento dos aglomerados subnormais, realizado pela SEMPLAN em 2016 mostra que a maioria deles se localizam na área consolidada da cidade. Especialmente, situados nos espaços vazios deixados no período de construção dos conjuntos habitacionais pela COHAB-PI, que construía seus empreendimentos em localidades afastadas do centro urbano (SILVA, p. 99, 2017.)

\section{OBJETIVOS}

Com base no arcabouço teórico e no panorama apresentado, o artigo em questão utiliza como objeto de estudo dois aglomerados subnormais, ambos localizados na região da zona Leste em Teresina - O Morro da Garrincha e Miranda Dantas. Busca-se fazer um estudo desses aglomerados, analisando sua infraestrutura, com base na lei dos direitos sociais, propondo aspectos negativos e positivos encontrados no local. 


\section{METODOLOGIA}

Os principais aspectos considerados na análise foram com base no artigo $6^{\circ}$ da Constituição, que prevê a garantia de direitos sociais a educação, a saúde, o trabalho, a moradia, o lazer, a segurança, a previdência social, a proteção à maternidade e à infância, a assistência aos desamparados (BRASIL, 1988). Foram realizadas visitas in loco e revisões da literatura acerca do urbanismo e dos aglomerados subnormais. Após a coleta de dados, foram analisados aspectos em relação a infraestrutura das habitações, vias de circulação, além de serviços públicos oferecidos na região.

\section{RESULTADOS}

Os aglomerados Miranda Dantas e Morro da garrincha se localizam no bairro Horto florestal, zona leste de Teresina (Figuras 1, 2 e 3). Uma área bem urbanizada, com uma infraestrutura de qualidade e serviços variados próximos. Em meio a esse contexto, surgem dois aglomerados que resistem até hoje, alguns ainda sem título de posse. Alguns aspectos mínimos foram analisados, com base no art. $6^{\circ}$ dos direitos sociais, que prevê a garantia de direitos sociais a educação, a saúde, o trabalho, a moradia, o lazer, a previdência social, a proteção à maternidade e à infância, a assistência aos desamparados. Diante da constituição, foram analisadas questões de infraestrutura das habitações, vias de circulação e serviços públicos oferecidos na região. 
Figuras 1, 2 e 3- Localização dos aglomerados.
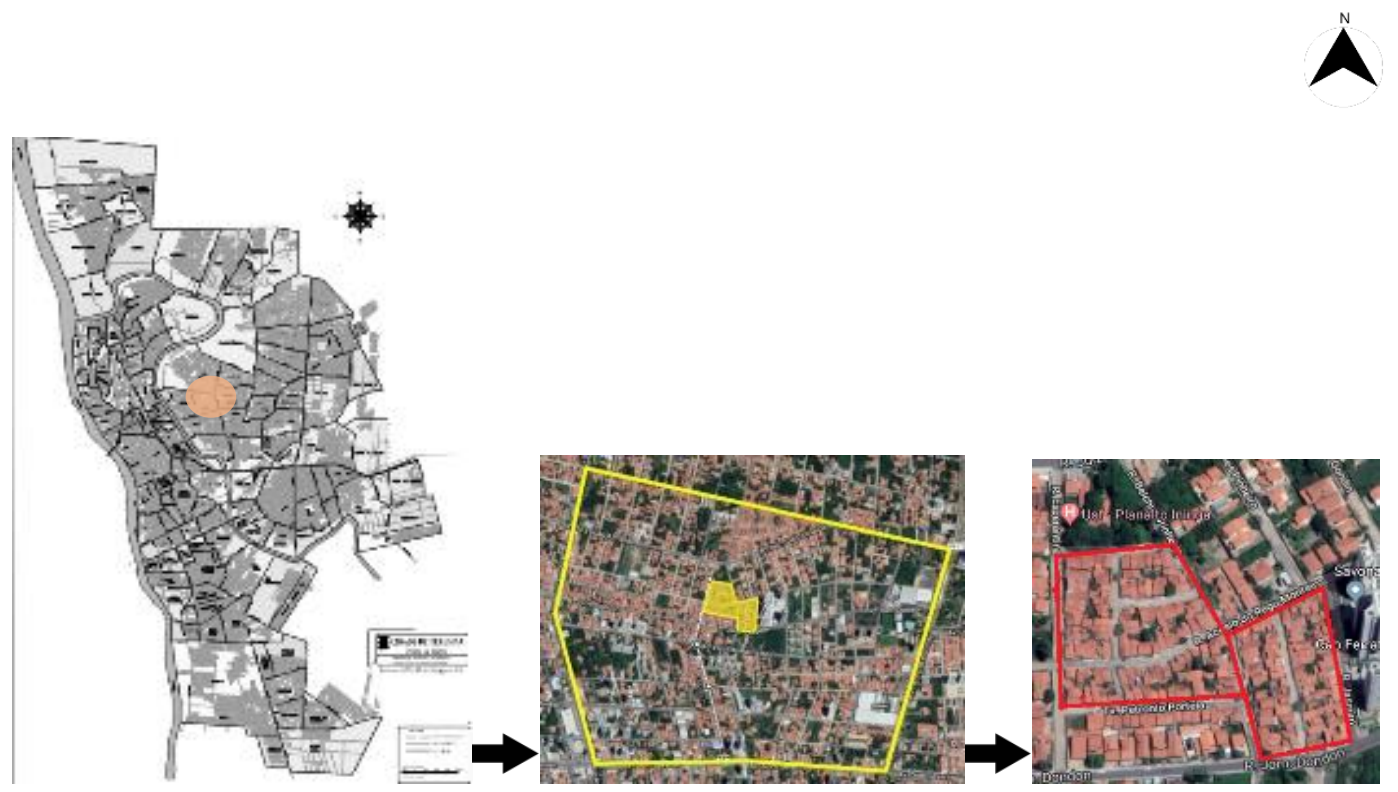

Fonte: Google maps (2018).

\subsection{Passeios públicos}

Tratando de infraestrutura e moradia, surgem os passeios, classificados em três categorias, passeios ausentes, passeios não conservados e passeios intrafegáveis (Figura 4). De acordo com o código de trânsito brasileiro, a calçada é "parte da via, normalmente segregada e em nível diferente, não destinada à circulação de veículos, reservada ao trânsito de pedestres e, quando possível, à implantação de mobiliário urbano, sinalização, vegetação e outros fins". Essa definição caracteriza a calçada como bem público, que é parte integrante das vias, pertencente ao município. O município não pode obrigar o proprietário a fazer ou regularizar sua calçada, mas pode incentivá-lo a fazer, entretanto, respeitando os padrões estabelecidos pela Lei das calçadas. 
Figura 4 - Calçadas ausentes, não conservadas e intrafegáveis, respectivamente.

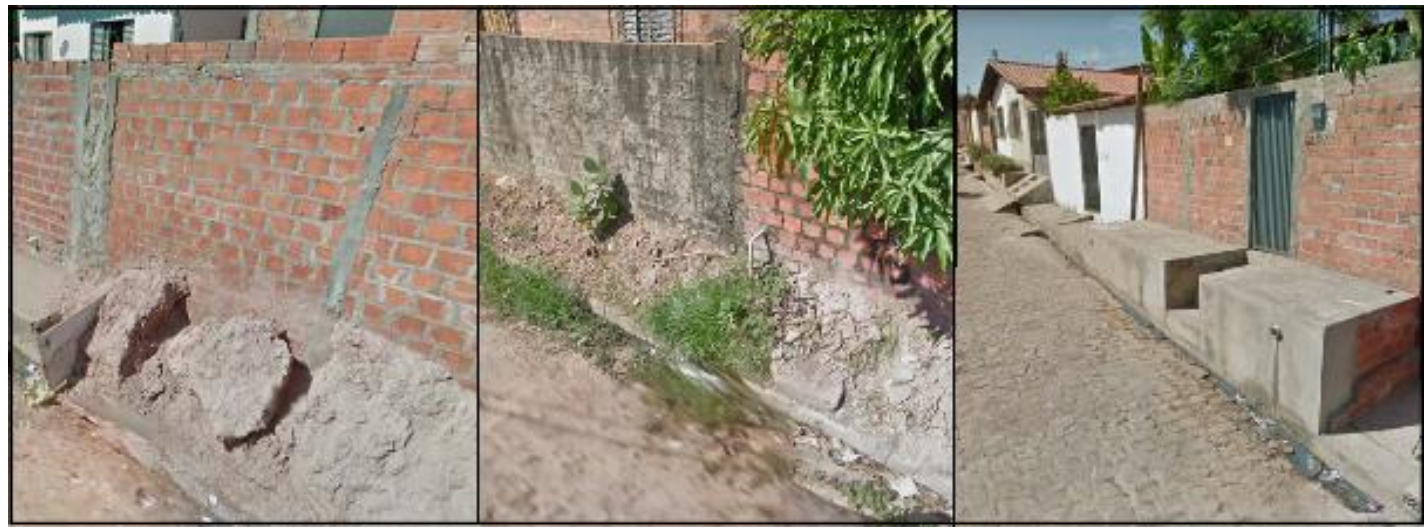

Fonte: Arquivo pessoal (2018).

A primeira imagem (Figura 4), caracteriza uma calçada ausente, onde a calçada é interrompida ao longo da rua, foi a tipologia menos encontrada nos aglomerados. A segunda imagem (Figura 4) mostra uma calçada malconservada, onde começa a se desenvolver uma vegetação e acúmulo de areia e pedras, gerando um difícil acesso. Já a terceira imagem (Figura 4), mostra uma calçada intrafegável, com diversos desníveis, acompanhando o padrão de cada edificação, sem levar em conta o pedestre. Em contraposição ao que se registra, a lei municipal de Teresina 4.522 estabelece novos padrões de calçadas, passeios públicos e critérios para a sua construção/reconstrução, conservação e utilização, considerando princípios como acessibilidade, segurança e autonomia, desenho urbano, nível de serviço e conforto e sustentabilidade. A lei das calçadas ainda diz que:

Faixa livre é a área acessível destinada à livre circulação de pessoas, desprovida de obstáculos permanentes ou temporários, com superfície regular, firme, contínua e antiderrapante sob qualquer condição, ficando fixada a largura mínima de 1,20 m (um metro e vinte centímetros) e largura recomendada de 1,50 m (um metro e cinquenta centímetros). (TERESINA, 2014, p. 3).

Pontos estes que como constatado não são levados em consideração, no momento da construção das vias públicas destinadas aos pedestres.

\subsection{Vias de circulação}

A pavimentação do local é com pedra poliédrica, rejuntado com pó de pedra e areia, sua largura é em média $8 \mathrm{~m}$ e não possui sinalização horizontal. A pedra poliédrica é uma das mais utilizadas para pavimentação, entretanto, é a que se desgasta mais rápido e ainda não possibilita a criação de uma superfície mais plana, por conta da irregularidade das pedras. Em diversos pontos das vias já há sinal de desgaste, com algumas pedras se soltando, dificultando o tráfego de veículos e pedestres (Figura 5). 
Figura 5 - Pavimentação poliédrica com patologia.

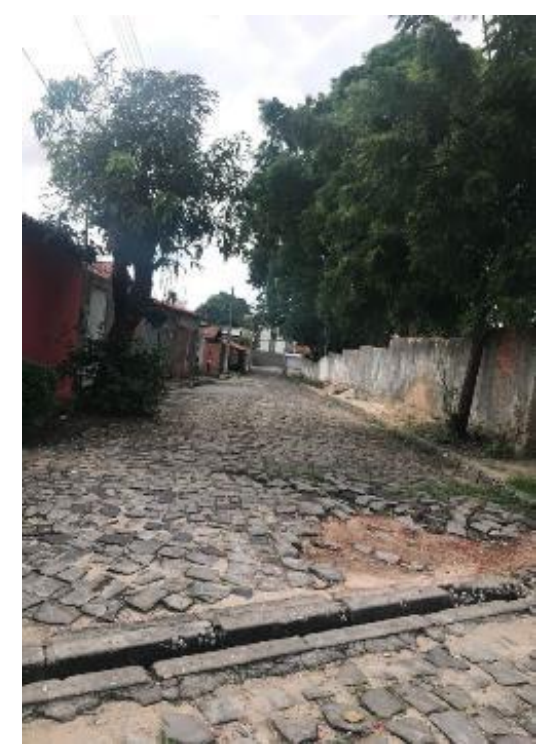

Fonte: Arquivo pessoal (2018).

\subsection{Saúde}

Nas proximidades há somente uma UBS - Unidade básica de saúde, que pode atender a demanda do aglomerado e regiões próximas, porém, de acordo com alguns moradores entrevistados, há uma carência de profissionais no local, não sendo estabelecido uma rotina de atendimentos com os pacientes, dificultando até mesmo o retorno dos mesmos. Muitos moradores acabam se vendo obrigados a procurarem por atendimento de saúde em outros pontos da cidade. Do ponto mais distante até a UBS (Figura 6), se percorre 461,29 metros. 
Figura 6 - Posto de saúde próximo aos aglomerados.

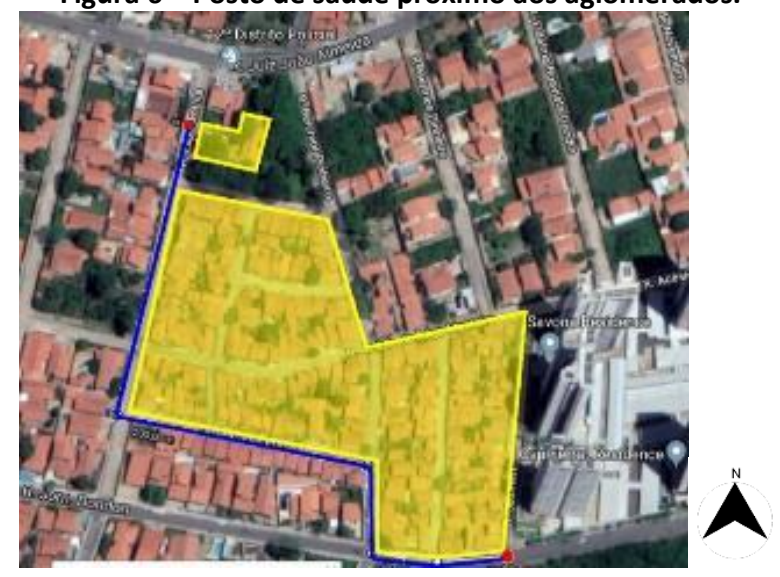

Fonte: Google mapas (2018).

\subsection{Educação}

Em relação a educação, existe apenas uma unidade escolar, Escola Municipal Noé Fortes, nas proximidades dos aglomerados. A escola oferece ensino fundamental e supletivo para jovens e adultos. Dessa forma, não se observa uma carência no quesito educação básica. A distância do último ponto até a escola é de 739,70 metros (Figura 7).

Figura 7 - Escola mais próxima dos aglomerados.

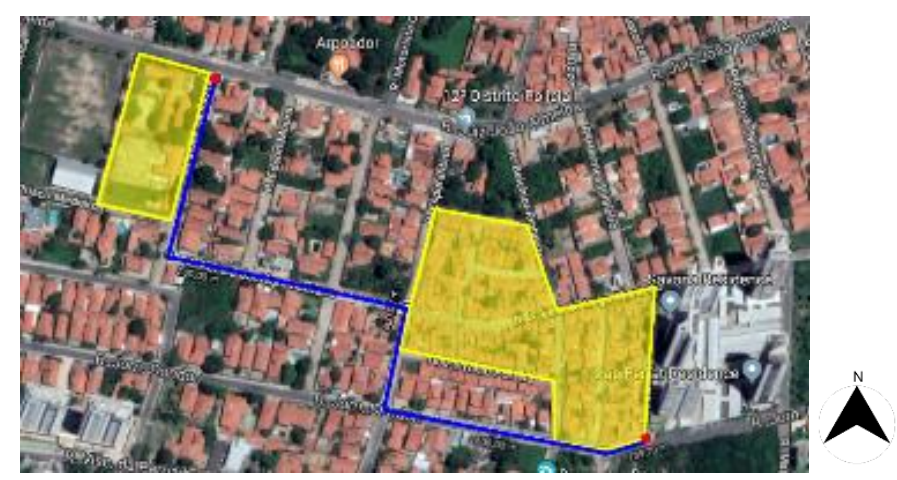

Fonte: Google mapas (2018).

\subsection{Saneamento}

Levando em conta as questões de saneamento em ambos os aglomerados, no que diz respeito ao que foi notado, observou -se que os mesmos possuem uma rede de esgoto que é responsável por contemplar e sanear o bairro, a tabela 2 logo abaixo apresentam dados da rede de esgotamento da região. 
Tabela 2 - Tabela rede de esgoto.

\begin{tabular}{|c|c|c|c|c|c|c|c|c|c|c|}
\hline \multirow{4}{*}{$\begin{array}{c}\text { Superintendência de } \\
\text { Desenvolvimento } \\
\text { Urbano (SDU) e Eairros }\end{array}$} & \multirow{4}{*}{ Aglomerados subnormais } & \multirow{2}{*}{\multicolumn{2}{|c|}{\begin{tabular}{|c|}
$\begin{array}{c}\text { Forma de abastecimento de } \\
\text { agua }\end{array}$ \\
\end{tabular}}} & \multicolumn{7}{|c|}{ Algumas características dos domicilios } \\
\hline & & & & \multicolumn{4}{|c|}{ Tipo de esgotamento sanitário } & \multicolumn{3}{|c|}{ Destino do Lixo } \\
\hline & & \multirow[b]{2}{*}{\begin{tabular}{|} 
Rede geral \\
de distribuiģão
\end{tabular}} & \multirow[b]{2}{*}{ Outra } & \multirow[b]{2}{*}{$\begin{array}{c}\text { Rede geral } \\
\text { de esgoto ou } \\
\text { pluvial }\end{array}$} & \multirow[b]{2}{*}{ Fossa séptica } & \multirow[b]{2}{*}{ Outra } & \multirow[b]{2}{*}{$\begin{array}{c}\text { Näo tinham } \\
\text { bahneirio ou } \\
\text { sanitario }\end{array}$} & \multicolumn{2}{|c|}{ Coletado } & \multirow[b]{2}{*}{ Outra } \\
\hline & & & & & & & & \begin{tabular}{|c|} 
Diretamente \\
por servigóde \\
limpeza
\end{tabular} & \begin{tabular}{|c} 
Em cacaamba \\
de saevicoode \\
limpeza
\end{tabular} & \\
\hline \multicolumn{2}{|c|}{ SDU LESTE (32) } & 10532 & 374 & 770 & 3674 & 6027 & 435 & 9050 & 566 & 1290 \\
\hline Horto & Miranda Dantas & 102 & & 2 & $9 \theta$ & 1 & & 102 & & \\
\hline Horto & Morro da Garrincha & 74 & & - & - & 74 & & 74 & & \\
\hline
\end{tabular}

Fonte: SEMPLAN (2010).

Entretanto algumas precariedades evidenciaram vários parâmetros, que apontaram para o fato de que, apesar de possuir uma rede de esgoto, os moradores dos aglomerados não possuem conexão a mesma, sendo feito o despejo inadequado de águas cinzas e esgoto diretamente nas sarjetas das vias, ou a utilização de fossa séptica, conforme comprovado nas figuras 9 e 10. Além disso as sarjetas não são adequadas para receber esse esgotamento que as casas direcionam.

Figuras 8 e 9 - Despejo de esgoto nas vias de circulação do aglomerado.

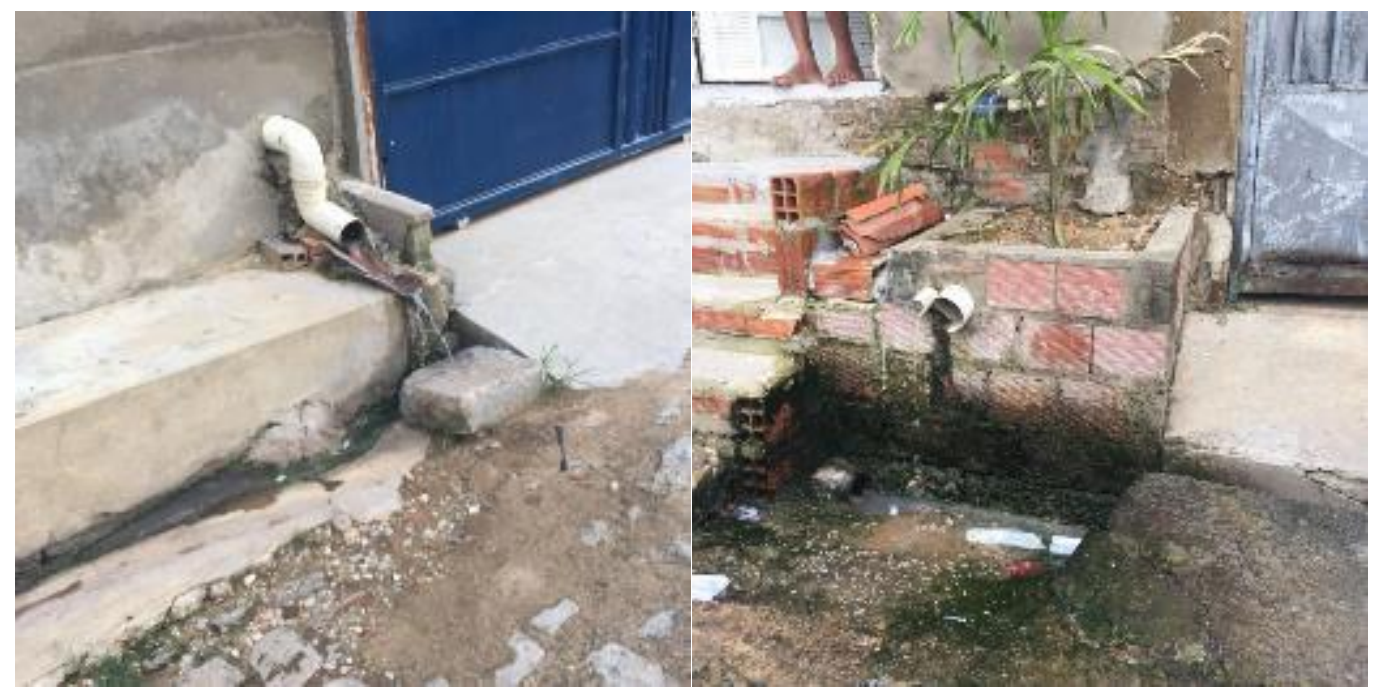

Fonte: Arquivo pessoal (2018).

Outros dois fatores agravantes que acentuam bastante a precariedade nesse ponto é a situação do recolhimento dos lixos dos moradores nas vias (Figura 11), e o caso da falta de direcionamento das águas (Figura 12), que não são drenadas e durante as chuvas fortes causam inundações para uma parcela de moradores, fato que compromete ainda mais as questões de saúde da população, contempladas nos direitos sociais. 
Figura 10 e 11 - Despejo de lixo e condições das vias que inundam durante as chuvas fortes.

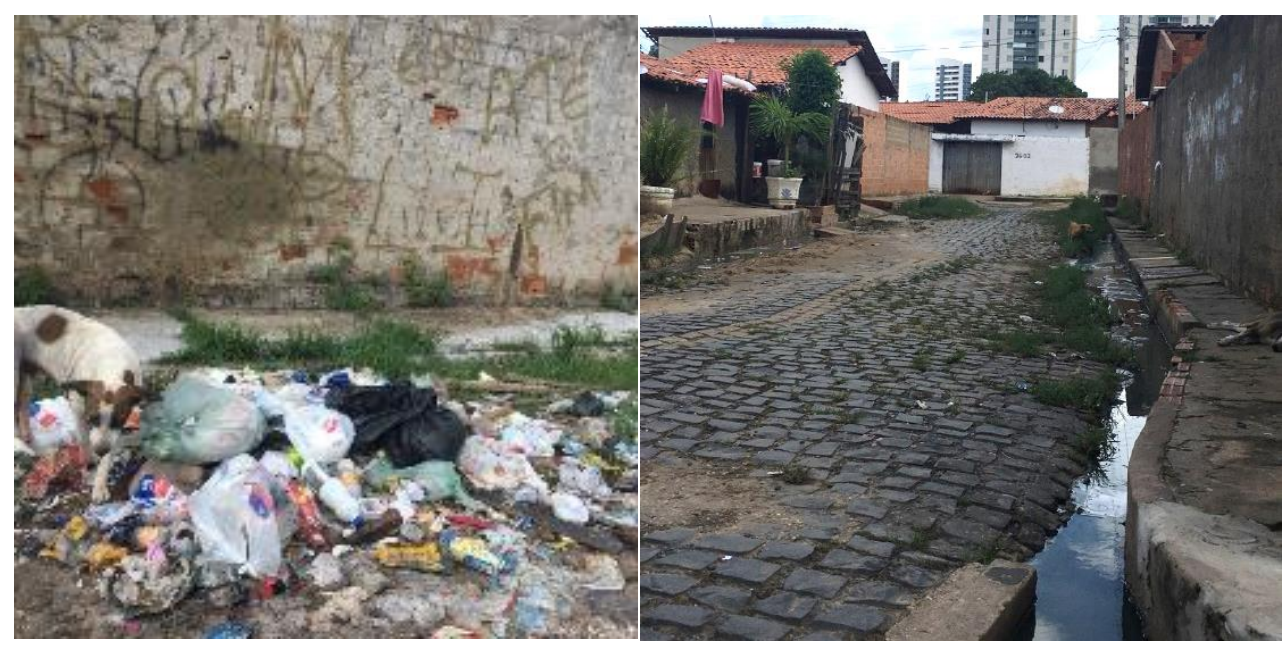

Fonte: Arquivo pessoal (2018).

\subsection{Lazer}

Quanto ao que assiste a questão do lazer básico para os moradores dessas áreas não foi detectado grandes problemas de carência, uma vez que, essa área é bastante privilegiada no que diz respeito a localização, a poucos metros de distância, os moradores dispõem de uma praça bem preservada (Figura 14), que apresenta manutenções e limpeza constante. A distância do ponto mais distante até a praça é de 373 metros (Figura 13).

Fonte: Google maps (2018)

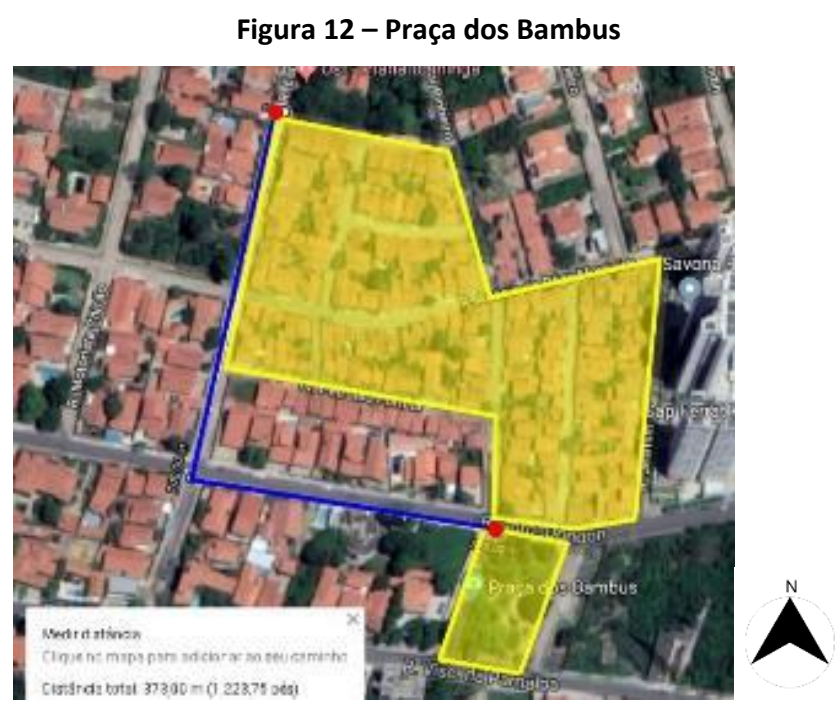


Figura 13 - Praça dos Bambus

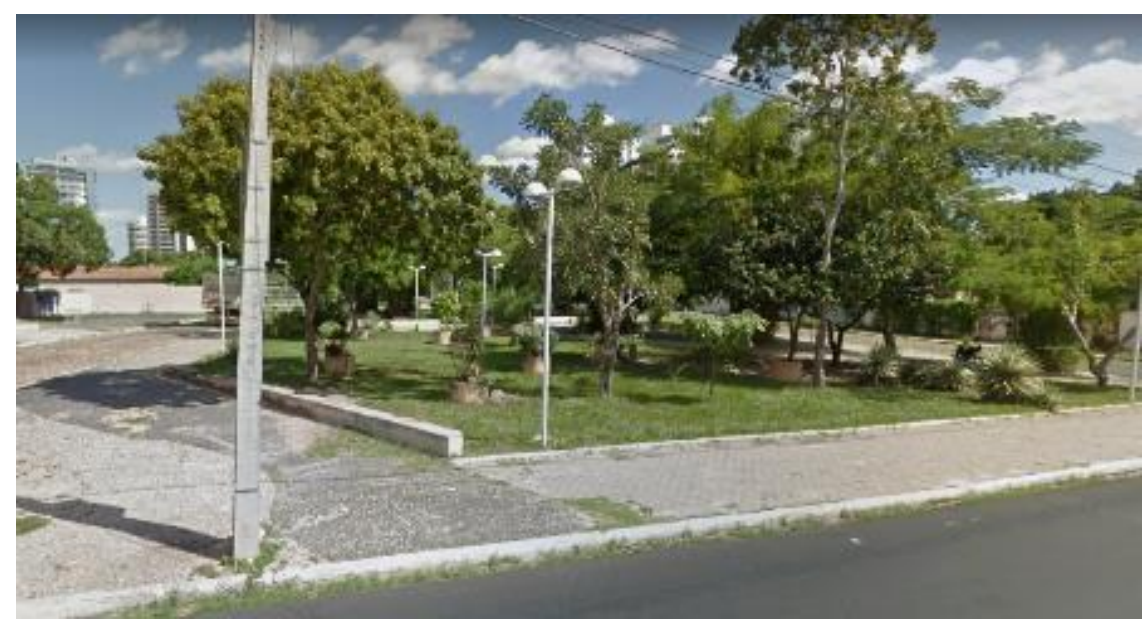

Fonte: Arquivo pessoal (2018).

O único problema observado, está na falta de qualidade do campo de futebol da escola Noé Forte (Figuras 16 e 17), que também serve a comunidade, mas apresenta problemas de manutenção, desgaste e falta de cuidado constante, evidentemente deixando a desejar no quesito de qualidade de condições para a prática de esportes como forma de lazer e entretenimento. Em compensação a quadra poliesportiva apresenta-se conservada, com alguns desgastes, mas com condições aceitáveis para pratica esportiva. A quadra se localiza a 676,36 metros de distância do último ponto (Figura 15).

Figura 14 - Campo de futebol e quadra poliesportiva pública.

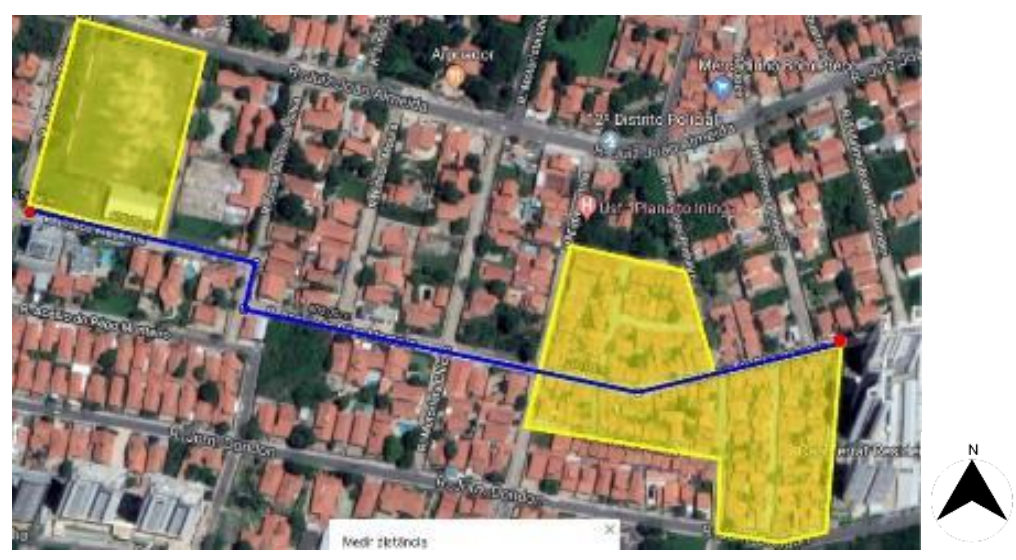

Fonte: Google maps (2018). 
Figura 15 e 16- Campo de futebol e quadra poliesportiva pública.

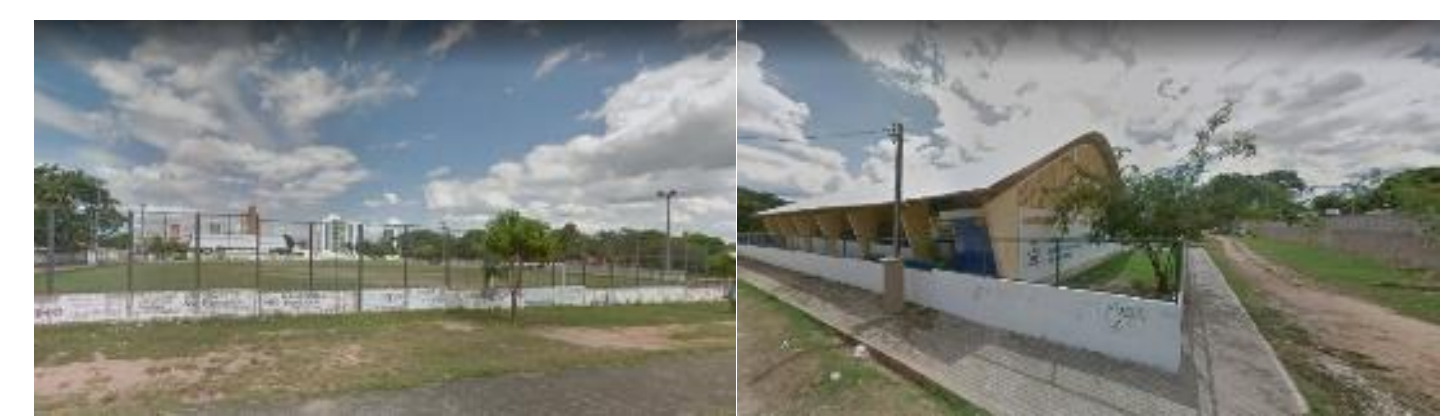

Fonte: Google maps (2018).

\subsection{Transporte}

Em relação a qualidade de locomoção através do transporte público desses moradores dos aglomerados, é que existe a ausência de pontos e rotas dentro das vias internas próximas, de modo que o usuário precise se deslocar uma distância não muito cômoda. As rotas mais próximas que acolhem essa área limitam as avenidas mais importantes responsáveis por limitar a área do bairro, o menor deslocamento que o usuário precisa fazer para usufruir do meio de transporte público é de 850 metros (Figura 18). Em 2015, o Instituto de Políticas de Transporte \& Desenvolvimento - ITDP, realizou um estudo que mede a distância ideal que um morador deve se deslocar até as estações de transporte público, essa pesquisa se intitula PNT (em inglês: "People Near Transit"). De acordo com a pesquisa, o tempo adequado, em termos de mobilidade urbana, é de 10 a 15 minutos de deslocamento a pé, o que equivale a aproximadamente $1 \mathrm{~km}$.

Figura 17 - Localização de referências do aglomerado em relação ao acesso ao transporte público.

Fonte: Google maps (2018).

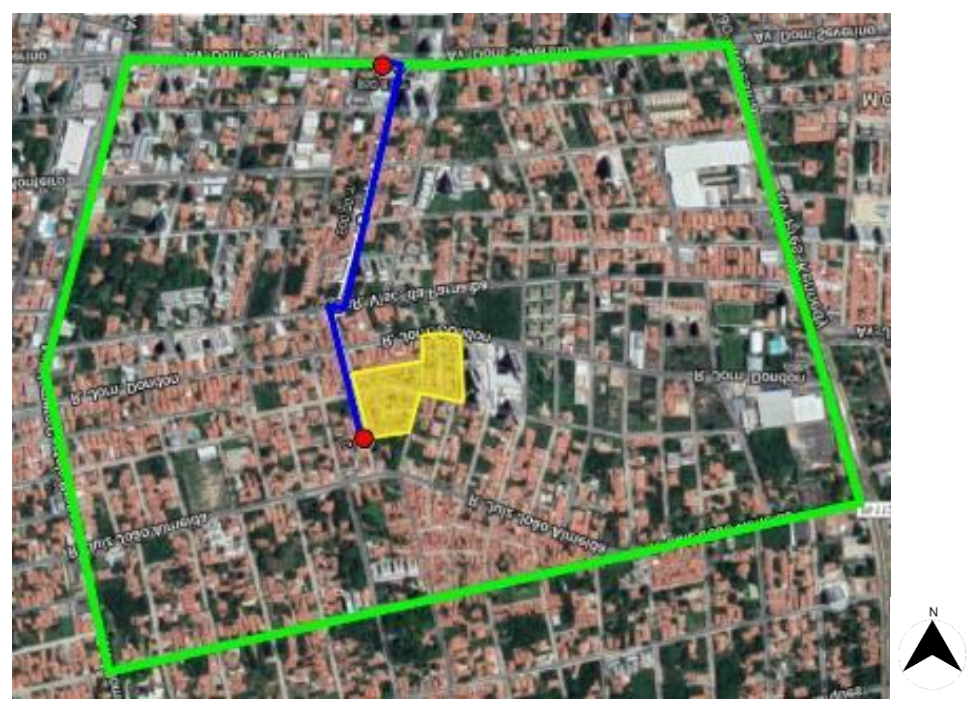




\section{CONCLUSÃO}

Após todas as análises, foi constatado que a população desses aglomerados não é assistida na maioria dos casos com serviços que são de direito guardados aos mesmos, concluiu-se então que, apesar de locar-se em um macro espaço bem estruturado da cidade, estes aglomerados não refletem em seu espaço a realidade do todo em que se inserem. Em virtude do que se concluiu, é notório a necessidade de muitas intervenções, dentre estas pode-se citar a melhoria do atendimento na UBS local; a substituição da pavimentação nas vias internas, afim de possibilitar o acesso do transporte público; a regularização dos passeios públicos; a conexão da rede de saneamento já existente nas habitações; e um plano de coleta regular de lixo.

\section{REFERÊNCIAS BIBLIOGRÁFICAS}

AGACHE, Alfred. Ed. Foyer Brésilien. Cidade do Rio de Janeiro, remodelação, extensão e embelezamento (Plano Agache). Rio de Janeiro,1930.

ASCHER, François. Os novos princípios do urbanismo. Livros Horizonte: Lisboa, 2010.

BRAZ E SILVA, Ângela Martins Napoleão. Planejamento e fundação da primeira cidade no Brasil Império, PROARQ 18.

COSTA, Nayane Áurea Santiago; et. al. O impacto do urbanismo moderno nos conjuntos habitacionais de Teresina: um olhar crítico. In: 11ㅇ SEMINÁRIO NACIONAL DO DOCOMOMO BRASIL. Anais. Recife: DOCOMOMO_BR, 2016. p.1-12.

D’ALENCASTRE, José Martins Pereira. Memoria chronologica, histórica e corografhica da Província do Piauhí. Revista do Instituto Geográphico e Histórico Brazileiro. Rio de Janeiro. t. XX, p. 5-165, 1ㅇtrimestre de 1857.

FERREIRA, Aurélio Buarque de Holanda. Novo Dicionário Aurélio Século XXI. Editora Nova Fronteira, 1999.

Instituto Brasileiro de Geografia e Estatística - IBGE. Censo Demográfico 2010. Aglomerados subnormais: primeiros resultados. Rio de Janeiro: IBGE, 2011. Acompanha 1 CD-ROM. Disponível em: <https://ww2.ibge.gov.br/home/estatistica/populacao/censo2010/aglomerados_subnormais/default_aglomerados _subnormais.shtm>. Acesso em: 20 abril.2018.

Instituto de Políticas de Transporte \& Desenvolvimento - ITDP. PNT (People Near Transit). Rio de Janeiro, 2015. Disponível em: <http://itdpbrasil.org.br/pnt/>. Acesso em: 4 jun.2018.

Instituto Brasileiro de Geografia e Estatística - IBGE. Regiões de influência das cidades: 2007. Rio de Janeiro: IBGE, 2008.

LE CORBUSIER. A Carta de Atenas. Tradução Rebeca Scherer. São Paulo: EDUPS, 1993.

LE CORBUSIER. Planejamento Urbano. Tradução Lucio Gomes Machado. 3 ed. São Paulo. Perspectiva, 2004.

LIMA, Antonia Jesuita de. As Multifaces da Pobreza: formas de vida e representações simbólicas dos pobres urbanos. Teresina. Halley, 2003.

LIMA, Antônia Jesuita de. Políticas urbanas, governos locais e segregação socioespacial: alcances e limites das novas intervenções públicas. Cidades Brasileiras: atores, processos e gestão pública, Belo Horizonte: Autêntica, 2007. 
LIMA NETO, Vicente Correia; KRAUSE, Cleandro; NADALIN, Vanessa Gapriotti. Distribuição de aglomerados subnormais na rede urbana e nas grandes regiões brasileiras - Brasília: Instituto de pesquisa econômica aplicada, 2014.

MARICATO, Ermínia. Urbanismo na periferia do mundo globalizado: metrópoles brasileiras. São Paulo Perspectiva, São Paulo, v. 14, n. 4, p. 21-33,

SILVA, Gracielly Portela da. Expansão do espaço urbano recente de Teresina (PI): uma análise do setor habitacional/ Gracielly Portela da Silva - 2017. 115 f.: il.

TERESINA. Empresa de Gestão de Recursos do Piauí (EMGERPI). Dados sobre os conjuntos habitacionais que foram construídos pela COHAB (PI) em Teresina, 2015.

TERESINA. Lei complementar $\mathbf{n}^{\circ}$ 4.522. Estabelece novos padrões de calçadas e critérios para a sua construção, reconstrução, conservação e utilização de calçadas no Município de Teresina, e dá outras providências. Teresina, 2014. Disponível em: <http://pgm.teresina.pi.gov.br/admin/upload/documentos/c3de78f447.pdf>. Acesso em: 5 jun.2018.

Secretaria Municipal de Planejamento e Gestão (SEMPLAN). Teresina: Dinâmica Populacão. PMT/SEMPLAN: Teresina, 2016. 